\title{
Marketing tools for managing consumer behaviour in the market of innovative products
}

\author{
Evgenii Konnikov ${ }^{1}$, Olga Volvach $^{1}$, Boris Lyamin ${ }^{1,}$, and Irina Kapustina ${ }^{1}$ \\ ${ }^{1}$ Peter the Great St. Petersburg Polytechnic University, 195251 St. Petersburg, Russia
}

\begin{abstract}
The article analyzes the existing approaches to managing consumer behavior. As a result, of the study, the need to manage consumer behavior in the field of innovative goods and services was identified. An analysis of existing methods and approaches to managing consumer behavior was carried out. A methodology was proposed for consistently changing the perception of innovative products by a potential consumer to improve the efficiency of innovative companies. The proposed methodology allows consistently adjusting the perception of a potential target audience through digital marketing tools. The application of the proposed methodology will significantly expand the base of the loyal target audience, which is converted into an increase in revenue, profit and other financial indicators of innovative companies.
\end{abstract}

\section{Introduction}

At present, in view of the crisis phenomena in the world economy, the issue of introducing innovative technologies both in existing sectors of the economy and the creation of new ones that are fundamentally different from existing industries, the combination of which can create an entire industry based on innovative technologies and new approaches to management, is especially urgent. The efficiency of innovative enterprises raises questions, since the combination of factors influencing their activities does not allow them to compete on an equal footing with existing organizations in the market. Despite this, scientific and technological progress, tightening of environmental legislation, increased consumer interest in innovative companies and their developments, as well as other factors allow innovative organizations to profit and develop. At the same time, proceeding from the diffusion of innovations for the mass use of innovative products, time is needed, differentiated depending on the type of products, however, there are marketing tools that can accelerate the adoption of innovations and significantly increase consumer loyalty to the product. For example, consider the renewable energy market.

The term renewable energy sources (RES) is used in relation to those sources whose reserves are practically inexhaustible, that is, they are replenished in a natural way, for example, solar energy, wind energy, energy of rivers and streams, energy of tides, geothermal energy, dissipated thermal energy: air heat, water, oceans, seas and reservoirs and biomass energy [1]. In Russia, the market for renewable energy sources is only gaining momentum, in 2019 their share in electricity production is $17.9 \%$. In general, green energy

${ }^{*}$ Corresponding author: lyamin.bm@gmail.com 
is attractive in our country because it can help transform idle or low-powered factories into useful production of commercial technologies. Wind turbines, solar thermal collectors are all material-intensive technologies that require skilled labor and well-equipped manufacturing facilities. There are significant barriers to realizing these opportunities, but market intermediation, joint ventures, and the enforcement of ISP regulations have a long way to go in overcoming these barriers. [2]

The problem of switching to RES is not only the high cost of electricity or dependence on natural conditions, but also the lack of public awareness of the possibilities of RES. For example, Russian citizens have a very low demand for energy generated from renewable sources and a lack of interest in environmental innovation, primarily due to a lack of awareness of the benefits of this sector and a lack of appropriate available opportunities. Lack of information on renewable energy costs, geographic resources and opportunities creates additional risk uncertainty for potential investors. Renewable energy sources have not previously received priority in the economic system, which is why there are not enough sources of information about them, and the lack of demonstration experience creates additional doubts about the effectiveness of technologies in Russian conditions.

One of the tasks of the marketing profile in this situation is to educate potential consumers about the features and details of the product, to refute, possibly, incorrect ideas about alternative energy. It is important to inform consumers about the level of efficiency and economic benefits that can be obtained by both the consumer at the individual level and the country as a whole. Despite the large amount of information available in the digital environment, it is worth considering the fact that each person has a unique way of thinking and the percentage of awareness on a particular topic is also different. Lack of sufficient knowledge of the subject raises risks and concerns that further affect consumer decisions.

Thus, the relevance of the need to use marketing tools to improve the efficiency of management of innovative organizations is beyond doubt. Let us consider in more detail the existing methodological tools developed by domestic and foreign scientists.

\section{Materials and Methods}

Increasing the efficiency of innovative organizations through the use of marketing tools allows you to purposefully address potential consumers of innovative products and inform them about the possible improvement of their quality of life through the use of an innovative product or service. Since there are a lot of developed marketing tools for influencing the consumer, we will consider in more detail the methodological approaches to managing consumer behavior of domestic and foreign scientists.

A team of authors I.F. Chepurova. and Presnyakov A.A. substantiated the role of marketing tools in the purchasing decision-making process. The authors differentiated the set of marketing tools into four groups of tools: problem analysis tools, differentiation tools, risk reduction tools and price tools. Each group of instruments corresponds to the stages of making a purchase decision:

- need identification - problem analysis tools;

- study of options - tools of differentiation;

- removal of objections - risk mitigation tools;

- negotiation of conditions - price instruments.

The proposed approach makes it possible to form a company's image consistently based on the stages of making a purchase decision, thereby forming a loyal audience for the brand. The tools for influencing the audience will be: classic methods of attracting clients, finding clients by using direct contact (cold calls), personal sales, attracting via SMS, emails, business cards, brochures, catalogs, groups in social networks. [3] Most of the 
proposed tools cannot be used to promote innovative products, since a potential consumer is not able to understand what are the advantages of an innovative product.

Research to assess the impact of digital marketing technologies on consumer decision making by O.Yu. Vinichuk. reveals that the introduction of digital technologies in the marketing activities of airlines intensifies the competition for the consumer and promotes the active use of digital marketing. The author conducted a study to assess consumer preferences at each stage of decision-making when choosing a service, presented a model of consumer behavior that takes into account the specifics of content perception at each stage of decision-making when choosing a service. The author has developed recommendations for companies to improve their marketing activities based on the use of optimal technologies and digital marketing tools (Table 1). [4]

The author chose the air transportation market as an object of research, in particular, the activities of airlines to attract customers.

Table 1. Recommendations for improving the marketing activities of Russian airlines using digital marketing technologies [4].

\begin{tabular}{|c|c|}
\hline Recommendations & Content \\
\hline $\begin{array}{l}\text { 1. Improving the content of } \\
\text { electronic pages }\end{array}$ & $\begin{array}{l}\text { - - generate information on electronic pages based on the } \\
\text { golden rule of content management; } \\
\text { - - use all types of content; } \\
\text { - - conduct contests, online research, polls, etc. }\end{array}$ \\
\hline $\begin{array}{l}\text { 2. Development and } \\
\text { implementation of a chat bot }\end{array}$ & $\begin{array}{l}\text { development of new software based on popular social } \\
\text { networks and communication applications. Allows you to } \\
\text { keep in touch with the consumer around the clock, save his } \\
\text { time and simplify the search for information }\end{array}$ \\
\hline $\begin{array}{l}\text { 3. Modernization of aviation } \\
\text { applications }\end{array}$ & $\begin{array}{l}\text { introduction of additional functions into the mobile } \\
\text { application: } \\
\text { - BagJourney system; } \\
\text { - transport schedule, taxi rating; } \\
\text { - - Meet \& Seat service }\end{array}$ \\
\hline 4. Create viral ads & $\begin{array}{l}\text { creating informal advertising materials that evoke an } \\
\text { emotional response from the consumer, increase the airline } \\
\text { brand awareness }\end{array}$ \\
\hline $\begin{array}{l}\text { 5. To improve the level of } \\
\text { comfort and quality of } \\
\text { passenger service at local } \\
\text { airports }\end{array}$ & $\begin{array}{l}\text { - - equipping airports with new equipment for screening } \\
\text { passengers; } \\
\text { - - installation of terminals for self-printing boarding pass } \\
\text { using a QR code }\end{array}$ \\
\hline $\begin{array}{l}\text { 6. Increase the level of comfort } \\
\text { and quality of passenger service } \\
\text { during the flight }\end{array}$ & $\begin{array}{l}\text { - control of the work of personal radios, televisions, } \\
\text { headphones; } \\
\text { - providing an available Wifi network in the salon }\end{array}$ \\
\hline
\end{tabular}

The author's recommendations are based on an in-depth analysis of airlines and digital marketing technologies. However, the proposed measures will be effective in the case when the market is formed and the target audience does not have a pronounced misunderstanding of the usefulness of the air transportation service, as for the market of innovative goods, it is characterized by a high degree of uncertainty about the need to purchase, therefore, a significant number of measures proposed by the author only applicable to airlines.

An especially interesting study can be considered the work of Sinyaeva I.M., who revealed the structure of the consumer behavior management system in the field of innovation, including such subsystems as modern marketing concepts, consumer behavior factors, loyalty programs and electronic support CRM. [5]

According to the author, the consumer behavior management system [Smc] represents a functional dependence on the constituent elements of three large subsystems: the subsystem 
of modern marketing concepts "M"; subsystem of factors of consumer behavior "4F"; customer loyalty subsystem "L":

$$
\mathrm{Smc}=\mathrm{f}(\mathrm{M} ; \mathrm{F} ; \mathrm{L})
$$

The consumer makes a decision to purchase an innovative product based on the influence of a combination of factors on it, which can be differentiated into four groups:

1. External factors, market environment, state of the economy, socio-demographic factors, technological factors

2. Marketing factors, product, price, distribution, promotion

3. Personal factors, personality type, economic situation, work, age, lifestyle

4. Psychological factors, needs, motives, perception, attitudes, beliefs, assessment.

The author argues that the development of a loyalty program is of great importance in the successful implementation of an innovative product. An example of the formation of a customer loyalty program - CS (Customer Satisfaction - customer satisfaction with a new product) is the best practices of the well-known Toyota company, which has achieved maximum customer satisfaction through high service and quality of service. [5]

The system of consumer behavior management proposed by the author comprehensively considers the management problem, combining the existing marketing concepts, i.e. the company needs to select a concept that will satisfy those needs of consumers that they themselves do not yet know about. Then, after choosing a concept, it is necessary to identify a set of factors influencing the decision to buy consumers, and finally, to build business processes in the organization in such a way that modern artificial intelligence tools are aimed at increasing the level of customer loyalty. However, it is worth noting that the developed system does not specify the magnitude of the influence of each factor on making a purchase decision; at the same time, the toolkit for influencing the consumer to increase his awareness of the innovative product is not noted.

A team of authors Bárbara Santos, Oscar Bernardes and Vanessa Amorim analyzed Digital Influencers and their impact on consumers by industry. As part of the study, an analysis of the effectiveness of using Digital Influencers for companies from various fields of activity was carried out, according to the results of the study, it was revealed that the influence of Digital Influencers on consumers from various fields of activity is differentiated, i.e. To get a significant effect from the use of Digital Influencers when promoting innovative products, it is necessary to carefully approach the choice of Digital Influencers. [6]

The team of authors Marina V. Melnichuk, Marina Belogash and Maria Pisonova investigated a more applied problem of the manipulative influence of texts advertising financial products. From an interdisciplinary point of view, the authors take a systematic and complex approach to the phenomenon of manipulative communicative influence on consumer behavior. The authors investigated linguistic means of all levels, capable of claiming the ability to manipulate and influence the neurophysiological and neuropsychological processes of consumers. On the basis of the conducted research of advertising texts of financial institutions, it was revealed that at the phonetic, morphological, semantic and syntactic levels, there are linguistic means with manipulative properties. They are realized in the complex interaction of all subsystems of manipulative communicative influence. Having studied financial slogans, image slogans and advertising texts, the authors identified a correspondence between specific language means, intentions, manipulation goals, thinking styles and neural processes. Thus, we can conclude that information is a tool for modeling consumer decision making, i.e. in order to motivate the consumer to purchase an innovative product, it is necessary not only to analyze his behavior, but also to inform him about the innovative product in the language the consumer speaks. [7] 
Finally, a team of authors Viktorija Kovanovienè, Raminta Mačyte, Rasa Petkevičiūtė and Greta Zaikauskaitè analyzed and evaluated the impact of marketing tools on consumer behavior. The authors' research has shown that the use of various marketing tools, such as advertising and online communication via social media or blogs, can attract the attention of businesses and have a positive impact on consumer behavior. On the other hand, the authors note that it is necessary to take into account both the micro- and macroenvironment, since people can make different decisions depending on the surrounding cultural, social and market conditions. On the basis of the authors' theoretical model of the influence of marketing tools on consumer behavior, there is a positive correlation between sociological variables, external incentives and marketing communications (Fig. 1). The holistic model should be empirically tested and revised after field research. [8]

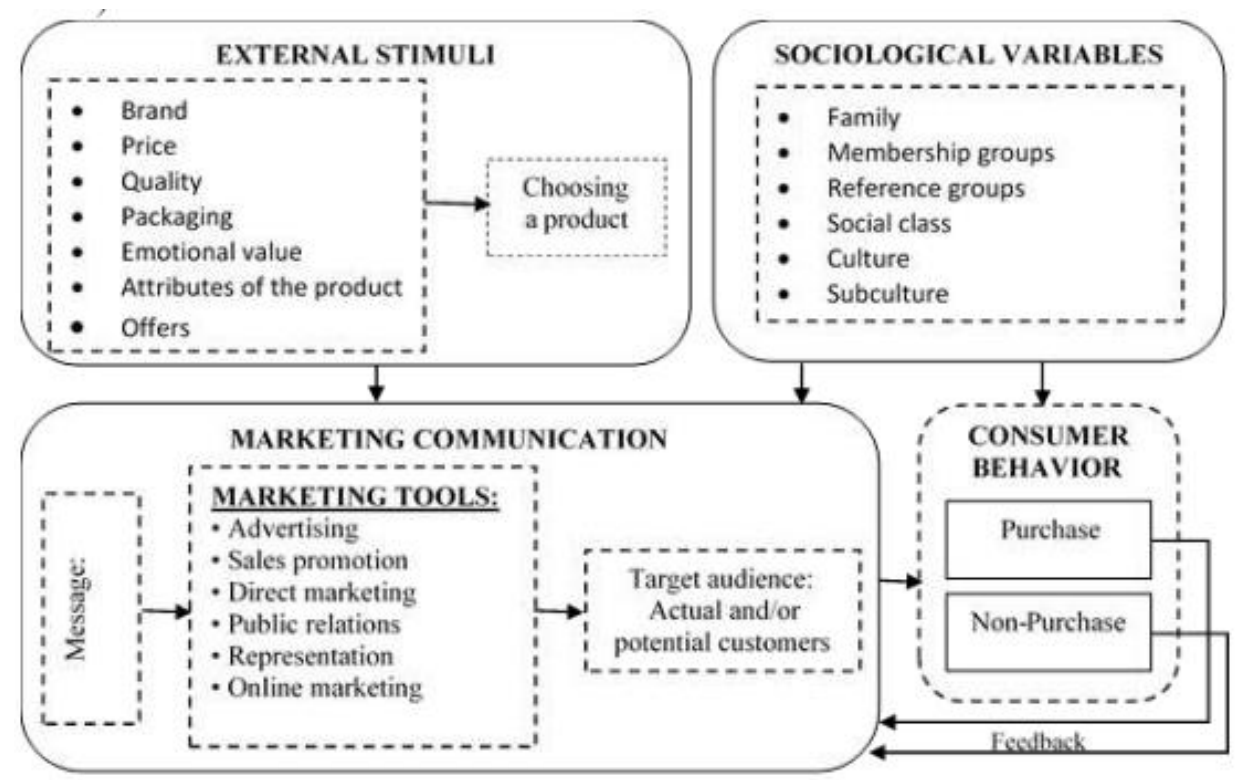

Fig. 1. Model of the influence of marketing tools on consumer behaviour [8].

Thus, the model developed by the authors reveals the influence of marketing tools on consumer behavior. The model assumes that there is a correlation between sociological variables, external stimuli and marketing communications, therefore, a combination of these factors can favorably influence purchasing behavior. Accordingly, it is necessary to offer marketing tools for assessing the degree of influence of each factor and assess the level of impact on the decision to purchase.

As a result of the analysis of existing methods and approaches to managing consumer behavior, it is necessary to conclude that the existing approaches are based on identifying a set of factors influencing consumer behavior and making a purchase decision, at the same time, the strength of influence of each of the identified factors is not specified depending on on the specifics of the product or service. It is especially worth noting the generalization of approaches to managing consumers of innovative products, which, of course, requires clarification. To do this, we will develop an algorithm for changing the perception of a potential consumer of innovative goods or services. 


\section{Results}

In the modern world of technology, the easiest way to influence a potential client is through a digital social environment, where information is available, and most importantly, easy to understand. It is important to analyze the potential consumer, his interests and awareness in the field of innovative products, for example, renewable energy sources. It is necessary to convey to the consumer in simple and understandable words what renewable energy sources are, what are their advantages for the environment and what are the benefits for the person himself. Alternative energy consumers are mainly innovators who can be easily interacted with, it is this type of consumer that can give feedback to companies about the imperfection of its product. For these users, it is important that the company provides consistent quality, product improvement, and maintains the infrastructure of products and services.[9-13]

Also, potential consumers may be household owners in regions isolated from electricity supply. Tariffs and prices for resources are increasing every year, and most of all this affects the remote areas of the country, where life support is carried out at the expense of imported fuel. In turn, the introduction of renewable energy sources will not only reduce energy costs, but also increase the reliability of energy supply in such areas, contribute to the creation of new jobs and improve the quality of life of consumers.

Hence the obvious question: how exactly to interest the consumer? For a situation of latent or latent demand, in which a potential consumer has a corresponding need, but he is not aware or little aware of a product or service that can satisfy it, it is advisable to use tools of the cognitive concept of marketing, namely, learning the technology of consumption of a product or service. [14] And, if we are talking about the situation of influencing the consumer using the capabilities of social networks, one of the most appropriate is the use of the Overton window principle, developed by the lawyer Joseph Overton, and also called the "discourse window". [15] The conceptual essence of the Overton window can be applied in cognitive marketing tools to consistently and inconspicuously introduce into the consumer's daily life a product that was previously considered useless or even unacceptable. Within the framework of this theory, 5 stages of public opinion are distinguished:

- Unthinkable;

- Radically;

- Acceptable;

- Reasonable;

- Right.

Consider the use of the Overton window principle to establish the necessary perception of renewable energy sources by potential consumer groups. To begin with, it is necessary to assess the market for private households or end customers. Alternative energy marketing should aim to ensure that the company and its products are perceived not only through their services, but through the very essence of the company and its client. The company may not be as important as the potential client's income, as his sense of participation in the preservation of the environment and caring attitude towards him.

The purpose of building marketing tools in a digital environment based on the Overton Windows principle is to consistently change the perception of renewable energy sources by potential consumers. This tool assumes a sequential solution of the following tasks: $[16,17]$

1. Analysis of information about a potential consumer through a digital social environment. At this stage, an array of interests of a potential consumer is formed, which can be added in the form of a hierarchically structured set of tokens.

2. Based on the comparison of the resulting array of a hierarchically structured set of tokens with the basic thematic array dedicated to renewable energy sources, a conditional 
"balancing coefficient" can be formed, reflecting the degree of representation of renewable energy sources in the field of interests of a potential consumer.

3. Based on the analysis results, a directed digital information flow is formed for a potential consumer, which can be conditionally divided into the following groups:

a. A stream containing information exclusively in the field of interests of a potential consumer.

b. A stream containing information exclusively about renewable energy sources.

c. A stream containing information about RES in the context of the field of interests of a potential consumer.

The flow ratio is determined by the previously calculated balancing factor.

4. The initially determined balancing coefficient is dynamically updated, and as it transforms, the ratio of the generated flows changes. It is assumed that as information about renewable energy is integrated into the usual information context of a potential consumer, he goes through the previously identified stages of the "Overton Window". As a result, a person becomes a "potential consumer" to whom the company can send commercial offers.

Graphically, this algorithm is shown in Figure 2.

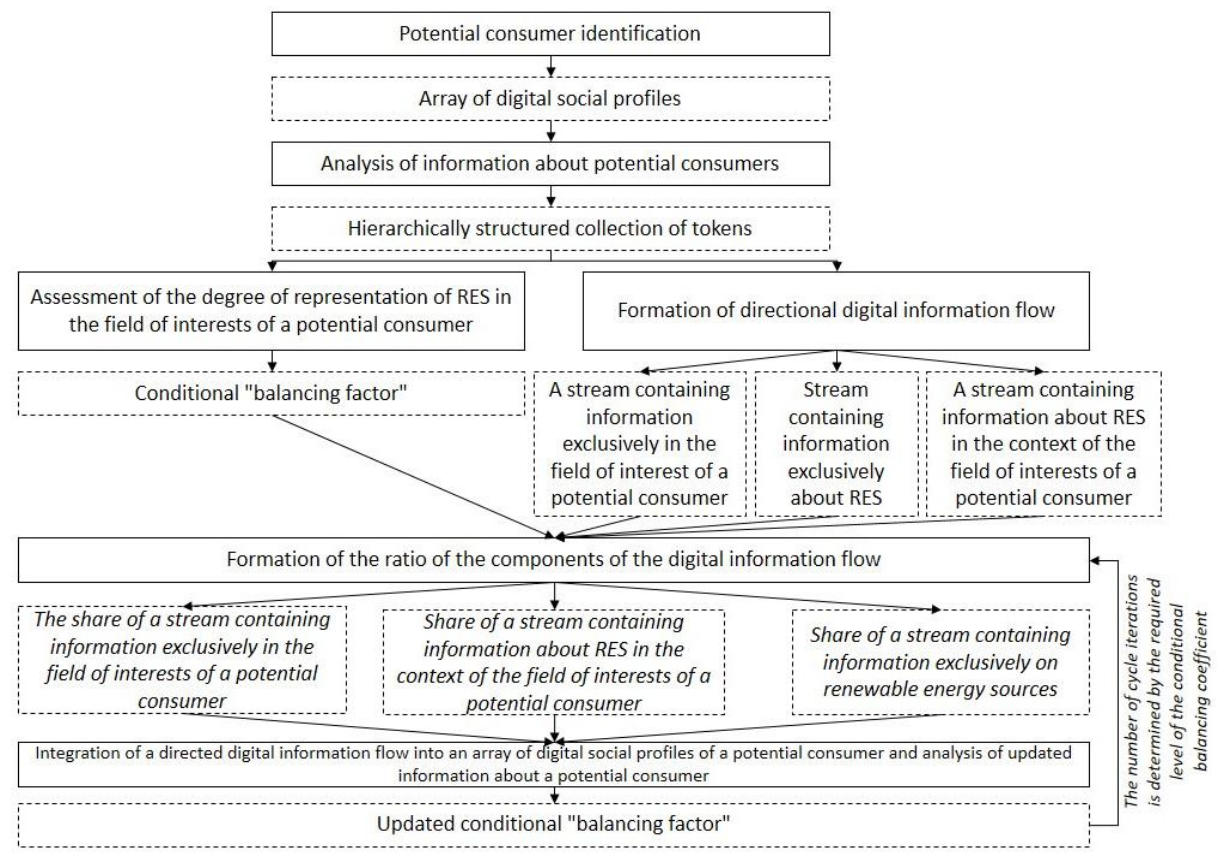

Fig. 2. Algorithm for sequential change in the perception of RES by a potential consumer.

The developed algorithm for the sequential change in the perception of renewable energy sources by a potential consumer first of all requires mathematical detailing. Each of the stages identified within the framework of the algorithm involves the formation of quantitatively specified arrays of information describing potential consumers.

As part of the primary stage, the search and identification of potential consumers is carried out. This stage is the most variable from the point of view of the approach to the formation of the final result. This thesis is primarily due to the multidimensionality of the possibilities of using RES-based energy generation technologies. Potential consumers of renewable energy sources can, first of all, be differentiated into a set of legal entities and a set of households. At the same time, the goal-setting of the subjects representing each of the 
aggregates can be fundamentally different. In particular, for legal entities, the following set of values formed by the use of renewable energy sources can be distinguished:

- Relatively low cost of generated energy.

- Relatively high level of energy independence / autonomy.

- Marketing effect caused by associative specificity.

This set of values can be extrapolated to households as well. Consequently, the process of identifying potential customers should primarily be based on a set of given values. The result of the implementation of this stage is an array of digital social profiles of potential consumers. These profiles can be determined based on the existing collection of social media such as Instagram, Facebook, Twitter and VKontakte. Each of the presented social networks has specific features, primarily in terms of the prevailing way of presenting content, and therefore the goal setting of the visit. Within the Russian Federation, the most common and universal in terms of the way of presenting content is the social network VKontakte. The overwhelming majority of the content consumed within this social network is consolidated within a single information flow specified depending on the user's preferences. Thus, the analytical basis of the developed algorithm can be limited exclusively to arrays of textual information.

The process of processing arrays of textual information presented in a natural form involves the selection of certain content characteristics of the content and their comparative quantification. This process involves the primary definition of elementary content units of text information, which are tokens.

For the purpose of assessing the presence of the RES topic, first of all, it is also necessary to present this content-thematic component with an array of tokens. Consequently, in parallel with the tokenization of arrays of textual information describing the information environment of potential consumers, it is necessary to tokenize an array of textual information describing the current topic of renewable energy sources. To assess the degree of representation of the RES topic in the information field of a potential consumer, you can use the following formula:

$$
K_{r, \theta . s .}^{i}=\frac{m\left(T_{i} \cap T_{r . e . s .}\right)}{m\left(T_{r, \theta . s .}\right)}
$$

where:

$\mathrm{K}^{\mathrm{I}}$ r.e.s - is the coefficient of the presence of the RES topic in the information field of a potential consumer i.

$\mathrm{Ti}$ - is a set of tokens describing the information field of potential consumer i.

Tr.e.s. - a set of tokens describing the current topic of renewable energy.

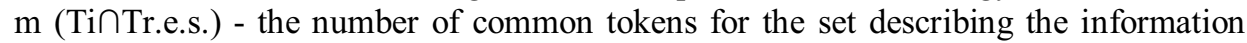
field of the potential consumer $i$ and the current topic of renewable energy.

$\mathrm{m}$ (Tr.e.s.) - the number of tokens in the set describing the current topic of renewable energy.

The calculated ratio is purely comparative and cannot be directly interpreted. First of all, this coefficient is necessary to determine the balance of the directed digital information flow, which makes it possible to gradually integrate RES in the field of interests of a potential consumer. The information field of a potential consumer, within the framework of the formed algorithm, can be differentiated into a directed digital information flow dedicated to renewable energy sources and the current information flow formed by the information environment of a potential consumer. In turn, the directed digital information flow can be differentiated into a flow containing information exclusively about RES and a flow containing information about RES in the context of the interests of potential consumers. The balance of these three streams is determined by the previously calculated 
coefficient of the presence of the RES topic in the information field of a potential consumer. The logic of the distribution of the specific weight between the streams is determined by the function of the sequential build-up of the RES topic. Since the proposed algorithm is based on the Overton Window principles, the primary stream is the stream containing information about RES in the context of the interests of potential consumers. Moreover, its specific weight should not exceed the conditionally permissible level. This thesis is due to the need to possibly limit the understanding of the integration process on the part of a potential consumer. Let us assume that the conditionally effective proportion of the distribution of the flow containing information on RES in the context of the interests of potential consumers is one to ten. Therefore, if the coefficient of the presence of RES in the information field of a potential consumer is $0.5 \%$, the effective share of the stream containing information about RES in the context of the interests of potential consumers will be $5 \%$. This proportion will make this information flow identifiable within the general information flow, and at the same time will not arouse suspicion on the part of a potential consumer. At the same time, a stream containing information exclusively about renewable energy sources is much more significant from the point of view of disseminating targeted information, but at the same time it is more likely not to arouse the interest of a potential consumer. Thus, it can be assumed that the effective proportion in this case will be one to one. Consequently, if the coefficient of presence of the RES topic in the information field of a potential consumer is $0.5 \%$, the effective share of the stream containing information exclusively about RES will be $0.5 \%$.

Thus, the fractional ratio of the components of the digital stream can be determined as follows:

$$
\begin{gathered}
d_{r, \theta, s_{1}}^{i}=K_{r, \theta, s_{1}}^{i} \times 10 \times k_{o n}^{i} \times N^{i} \\
d_{r, \theta, s_{x_{2}}}^{i}=K_{r, \theta, s_{1}}^{i} \times k_{o n}^{i} \times N^{i} \\
d_{c, i,}^{i}=k_{o n}^{i} \times\left(N^{i}-d_{r, \theta, s_{,},}^{i}-d_{r, \theta, s_{2}}^{i}\right)
\end{gathered}
$$

where:

dr.e.s. 1 - the number of information flow units containing information about RES in the context of the interests of a potential consumer $i$.

kon - coefficient of presence of potential consumer $i$ in the social network.

$\mathrm{N} \mathrm{i}$ - a set of potential units of content shown to a potential consumer i.

d r.e.s. 2 - the number of information flow units containing information exclusively on renewable energy sources.

dc.i. - the number of information flow units containing information exclusively in the field of interests of the potential consumer $i$.

Based on the calculated quantitative parameters, first of all, the number of content units dedicated to RES is determined. The selection of this content is made expertly, or can be partially automated.

The formed array of information units dedicated to RES should be sent to the information field of a potential consumer. This process assumes the following possible tools:

Direct, non-personalized direction of information units dedicated to renewable energy sources into the information field of a potential consumer through existing communication channels.

Direct, efficiently affiliated direction of information units dedicated to renewable energy sources into the information field of a potential consumer through existing communication channels. 
Integration of a directed information flow dedicated to renewable energy sources into the information flow generated by the sources of the information flow that is basic for a potential consumer.

Integration of a directed information flow dedicated to renewable energy sources into the information field of a potential consumer as targeted advertising. For the purposes of the generated algorithm, this tool is the most balanced, since it assumes a significant probability of reaching a potential consumer by the generated information flow dedicated to renewable energy sources and does not require the formation of complex social contacts. From an economic point of view, this tool is certainly costly, since each targeted message displayed is paid separately, however, this costs are predictable.

Of course, these tools can be used in parallel and balanced against the specifics of the potential consumer and the capabilities of the beneficiary. However, the fourth tool targeted advertising - is the most versatile and expedient to use.

\section{Discussion}

Based on the results of the integration of the generated information flow on renewable energy sources into the information field of a potential consumer, it is necessary to analyze the dynamics of the ratio of the presence of renewable energy sources in the information field of a potential consumer. Since this coefficient is not determined on the basis of the actual information flow directed at a potential consumer within a particular social network, but is determined solely on the basis of quantification of the potential information flow, it can be assumed that a potential consumer, when showing interest in content dedicated to renewable energy sources, will be integrate this topic into your information field (join the relevant communities, seek information on renewable energy sources, and simply spend more time reading the demonstrated targeted advertising dedicated to renewable energy sources), which in turn will certainly be taken into account by the algorithms of the social network.

Thus, in the information field of a potential consumer, the RES topic may begin to acquire a greater specific weight, which will undoubtedly affect the calculated coefficient. An increase in this coefficient will inevitably lead to an increase in the directed information flow dedicated to RES in the general information flow of a potential consumer. The result of the described process will inevitably be the penetration of the RES topic into the area of passive (at least) interests of a potential consumer, or at least this topic will become commonplace for a potential consumer, which in turn will lead to a potential consumer's understanding of possible solutions to the energy problems assigned to him and the use of technological solutions based on renewable energy sources.

\section{Conclusion}

Thus, as a result of the study, the need to manage consumer behavior in the field of innovative goods and services was identified. An analysis of existing methods and approaches to managing consumer behavior was carried out. Existing approaches are based on identifying a set of factors that affect consumer behavior and his decision to purchase, however, the strength of the influence of each of the identified factors, depending on the specifics of the product or service, is not specified. A methodology was proposed for consistently changing the perception of renewable energy sources by a potential consumer to improve the efficiency of companies in the field of renewable energy. The proposed methodology allows consistently adjusting the perception of a potential target audience through digital marketing tools. The application of the proposed methodology will 
significantly expand the base of the loyal target audience, which is converted into an increase in revenue, profit and other financial indicators of innovative companies.

\section{References}

1. E.A. Konnikov, R.D. Mansurov, P.S. Mikheev, and B.S. Niemb, Economic Sciences 132 (2020)

2. E.A. Konnikov and O.A. Konnikova, Bulletin of the Altai Academy of Economics and Law 50 (2020)

3. I.F. Chepurova and A.A. Presnyakov, Socio-economic phenomena and processes 12 (2017)

4. O.Yu. Vinichuk, Practical Marketing (2019)

5. I.M. Sinyaeva, Marketing and Logistics 106 (2017)

6. B. Santos, Ó. Bernardes, V. Amorim, Sustain. Bus. Int. J. 1 (2021)

7. M. Melnichuk, M. Belogash, M. Pisonova, XLinguae 13, 235 (2020)

8. V. Kovanovienè, R. Mačytè, R. Petkevičiūtè, G. Zaikauskaitè, Vilnius Univ. Open Ser. 42 (2019)

9. B. Lyamin, E. Konnikov, A. Furin, V. Kuzmenko, I. Andronov, Proc. Int. Sci. Conf. Digit. Transform. Manuf. Infrastruct. Serv. (Association for Computing Machinery, New York, NY, USA, 2020)

10. E. Konnikov, O. Konnikova, V. Leventsov, IOP Conf. Ser. Mater. Sci. Eng. (IOP Publishing, 2019)

11. B.F. Zabelin and E.A. Konnikov (2019)

12. G.C. González, R.H. Mar, Rev. Sci. Gest. (2010)

13. S. Datta, M. Saad, D. Sarpong, Technol. Forecast. Soc. Change 143, 27 (2019)

14. O.U. Yuldasheva and O.A. Pogrebova, Scientific Journal of the Russian Gas Society 23 (2017)

15. A.P. Gulivatenko, Russia and world development trends, 102-107 (2015)

16. D.G. Rodionov, S.V. Yalymov, and E.A. Konnikov, Economic Sciences 86 (2020)

17. B.F. Zabelin, E.A. Konnikov, V.M. Nikishin, K.K. Khatanzeisky, and D.F. Drobintseva, Economic Sciences 111 (2020) 